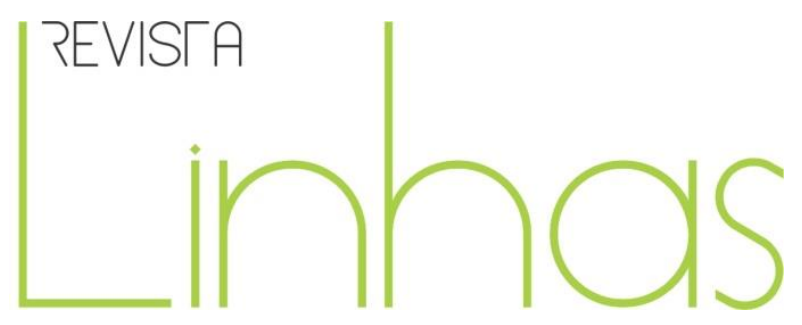

\title{
Os professores de Educação Física e a conjuntura estabelecida na rede escolar de ensino do Mato Grosso
}

\begin{abstract}
Resumo
Para que possamos entender as realidades vividas pelos professores de Educação Física na educação básica, se faz necessário possibilitarmos que esses sujeitos possam se expressar. As vozes ecoadas podem retratar para além dos problemas vivenciados diariamente, apresentar algumas possibilidades didático-pedagógicas adotadas diante das situações imperfeitas. A questão-problema elaborada foi: em que contexto está inserida a Educação Física como componente curricular nas unidades escolares do Mato Grosso? O objetivo geral foi analisar o contexto escolar dos professores de Educação Física a partir da realidade apontada pelos docentes em exercício. A metodologia adotada foi a pesquisa descritiva qualitativa. Os sujeitos do estudo foram 21 professores de Educação Física que se encontravam em exercício na rede pública do Estado do Mato Grosso. A coleta de dados se deu por meio do questionário e, a análise dos dados pelos eixos temáticos a partir dos procedimentos adotados por Rinaldi (2009, p.14). Os principais resultados apontaram que além do espaço físico ausente ou inadequado, e da escassez de materiais pedagógicos para as vivências, que a aversão dos alunos frente aos conteúdos propostos pelos professores e a indisciplina dificultam o processo ensino aprendizagem. Para o enfrentamento da realidade vivida os professores utilizam a criatividade, as adaptações de materiais e espaços e a construção de materiais alternativos. Dessa forma, se faz urgente e necessário que os professores de Educação Física demarquem seus territórios nas unidades escolares, a partir da superação das dificuldades instaladas e do compromisso profissional que transcende o dar aulas.
\end{abstract}

Palavras-chave: Professores de educação física. Escolas. Mato Grosso.

\section{Para citar este artigo:}

FERREIRA, Robson Alex. Os professores de Educação Física e a conjuntura estabelecida na rede escolar de ensino do Mato Grosso. Revista Linhas. Florianópolis, v. 20, n. 44, p. 203-232, set./dez. 2019.

\author{
Robson Alex Ferreira \\ Universidade do Estado do Mato \\ Grosso - UNEMAT - \\ Cáceres/MT - Brasil \\ alexrreiracaceres@gmail.com
}




\title{
The teachers of physical education and the settlement established in the school of teaching of Mato Grosso
}

\begin{abstract}
So that we can to understand the realities experienced by Physical Education teachers in basic education, it is necessary to enable these subjects to express themselves. These echoed voices can portray beyond the problems experienced daily, to present some didactic pedagogical possibilities adopted in the imperfect situations. The elaborate problem issue was: in what context is Physical Education included as a curricular component in the school units of Mato Grosso? The general objective was to analyze the school context of Physical Education teachers based on the reality pointed out by teachers. The methodology adopted was qualitative descriptive research. The subjects of the study were 21 Physical Education teachers who were working in public networks in the State of Mato Grosso. The data collection was done through the questionnaire and data analysis by the thematic axes from the procedures adopted by Rinaldi (2009, p.14). The main results pointed out that in addition to the absent or inadequate physical space and the lack of pedagogical materials for the experiences, that the students' aversion to the contents proposed by the teachers and the indiscipline makes the learning teaching process difficult. For facing the lived reality, teachers use creativity, adaptations of materials and spaces and the construction of alternative materials. In this way it is urgent and necessary that Physical Education teachers demarcate their territories in the school units from the overcoming of the installed difficulties and the professional commitment that transcends the teaching.
\end{abstract}

Keywords: Physical education teachers. Schools. Mato Grosso. 


\section{Introdução}

Para que possamos compreender criticamente as realidades enfrentadas pelos professores de Educação Física (EF) em seu dia a dia na rede de ensino, uma ferramenta significativa é darmos vozes a esses profissionais engajados nas mais distintas escolas da educação básica. O profissional de EF, durante o processo de formação na universidade, deveria possuir subsídios que ultrapassassem técnicas de como ensinar, ou ainda, confrontar a literatura com a realidade vivida por grande parte dos professores da educação básica. Para isso, confrontar a literatura com a realidade escolar é fundamental para que os futuros professores possam vivenciar não apenas situações hipotéticas, mas, sobretudo, as situações como são de fato.

O despreparo dos professores frente às realidades instaladas pode estar representando um abismo entre as teorias adotadas pelos professores universitários para a formação de docentes e os problemas enfrentados por esses profissionais no ambiente de trabalho, como apontam os estudos de Gatti (2014) e Herculano (2011).

Isso porque, possivelmente, ao abordarem as questões referentes ao processo ensino aprendizagem, a literatura que os orienta pode estar contribuindo para a formação de profissionais em ambientes ideais, nos quais prevalece a harmonia nas distintas relações estabelecidas entre elas. Bem como nas relações entre professores e alunos, alunos e alunos, professores e grupo gestor, em contraposição aos ambientes onde há, por exemplo, a indisciplina dos alunos, a indisposição para aprender e as condições inadequadas para o trabalho.

Acreditamos que a Resolução $\operatorname{CNE} n^{\circ} 2$, de $1^{\circ}$ de julho de 2015, que define as Diretrizes Curriculares Nacionais para a formação inicial em nível superior (cursos de licenciatura, cursos de formação pedagógica para graduados e cursos de segunda licenciatura) e para a formação continuada, definindo os princípios, fundamentos, dinâmicas formativas e procedimentos a serem observados nas políticas, na gestão e nos programas e cursos de formação, bem como no planejamento, nos processos de avaliação e de regulação das instituições de educação que as ofertam pode contribuir para que inexista um distanciamento tão significativo entre o que se aprende na universidade e o que de fato ocorre no ambiente escolar de trabalho (BRASIL, 2015). 
A Resolução estabelece que as instituições formadoras devem fazer a formação inicial em articulação/colaboração com os sistemas de ensino, bem como reconhecem as escolas de educação básica como espaços necessários à formação do profissional do magistério, e que, portanto, o estudante de licenciatura deve ser inserido em escolas públicas, pois é esse o espaço privilegiado das práxis docentes. Essas novas diretrizes atendem a um desejo histórico dos profissionais do magistério no que se refere à valorização dos profissionais ao envolver de modo articulado pontos referentes, dentre outros, à formação inicial e continuada, condições de trabalho e ao salário dos professores. Essa articulação entre a educação básica e as instituições que formam professores, tem por eixo uma compreensão formativa e indutora de desenvolvimento institucional que "redimensiona a formação desses profissionais a partir da concepção de docência que inclui o exercício articulado nos processos ensino e aprendizagem, organização e gestão da educação básica” (DOURADO, 2015, p. 315 - 316).

Cremos que o PIBID (Programa Institucional de Bolsas de Iniciação à Docência) seja o programa que melhor se aproxima dos anseios que almejam o incentivo e a valorização do magistério, por meio do aperfeiçoamento do processo de formação de docentes para ingresso na educação básica, no entanto, ao não poder atender a todos os futuros professores, ele acaba se tornando limitado (FERREIRA, 2016).

A EF escolar, ao longo de sua história, foi caracterizada de acordo com os anseios institucionais, políticos, sociais e pedagógicos que marcaram períodos específicos da história brasileira. Esses anseios sobrevivem até hoje nas mais distintas aulas de EF espalhadas Brasil afora, como aponta Benvegnú Júnior (2011). Em decorrência dos objetivos que caracterizaram cada época, podemos encontrar já há algum tempo, uma série de predicados atribuídos à disciplina e, consequentemente, aos professores que ministram a EF na escola. Dentre eles, percebemos no decorrer de uma década atuando na EF escolar, que ainda há enraizada no ambiente escolar uma desvalorização da disciplina, como apontam os trabalhos de Damázio e Silva (2008), Loyola, Fonte e Figueiredo (2010) e Oliveira e Daólio (2014), seja pela compreensão do significado da EF a partir do ponto de vista dos professores de outras disciplinas, do grupo gestor da escola, dos alunos e, até mesmo, dos próprios professores de EF. 
Para um grande número de professores de outras disciplinas, a EF no ambiente escolar se resume a práticas de determinado esporte. Essa prática, na percepção desses docentes, contribui para o extravasamento de energia dos alunos considerados mais difíceis em sala de aula, bem como é considerada como momento livre para os alunos, em que não há o que se aprender que não esteja resumido a práticas corporais desvinculadas da capacidade do pensar. Também temos que considerar que há professores de EF contribuindo para a imagem negativa da disciplina na escola, quando, por exemplo, suas aulas se resumem - do início ao fim do ano - à atividade livre, em que na grande maioria das vezes, opta-se pelo fazer, sem a compreensão do porque se está fazendo. Estas atividades acabam privilegiando aqueles indivíduos dotados de alguma técnica desportiva, como descrevem em seus estudos Faggion (2011) e Tenório e Silva (2013).

No entanto, também temos que destacar que há outros fatores que contribuem para a desvalorização da disciplina EF na escola, como por exemplo, uma formação inicial que pouco contribui para as resoluções dos problemas existentes nas escolas básicas e as condições de trabalho que acabam neutralizando as ações dos professores bem intencionados. Logo, a complexidade que envolve ser professor na educação básica deve ser considerada por todos os docentes na universidade, que deveriam estar constantemente em contato com o "chão da fábrica" (a escola), a fim de evitar uma disparidade entre a escola ideal e a escola real.

A questão-problema que norteou este trabalho foi: em que contexto está inserida a Educação Física como componente curricular nas unidades escolares do Mato Grosso?

O objetivo geral foi analisar o contexto escolar dos professores de EF a partir da realidade apontada pelos docentes em exercício no estado do Mato Grosso.

Acreditamos que essa análise pode contribuir para que surjam percepções carregadas de criticidade aos profissionais de educação, em especial aos de EF, ao compreenderem a realidade profissional destes professores que se encontram em exercício nas mais distintas escolas. 


\section{A formação do professor de Educação Física e a Educação Física na escola}

Na Resolução CNE $n^{\circ}$ 2, de $1^{\circ}$ de julho de 2015, que define as Diretrizes Curriculares Nacionais para a formação inicial em nível superior (cursos de licenciatura, cursos de formação pedagógica para graduados e cursos de segunda licenciatura) é estabelecido no Artigo 2, que "no exercício da docência, a ação do professor é permeada por dimensões técnicas, políticas, éticas e estéticas por meio de sólida formação, envolvendo dentre outros fatores, o domínio e manejo de conteúdos, metodologias e inovações" (BRASIL, 2015, p. 296), elementos estes que favorecem o desempenho desse profissional.

Sem ter a pretensão de esgotar o termo "formação sólida" contido como no artigo destacado, entendemos que ele é caracterizado como a formação que possibilita ao professor ser protagonista crítico e ativo das exigências que surgem em seu dia a dia, a partir da construção de conhecimentos diversificados que satisfazem as necessidades reais dos professores em exercício e dos futuros docentes.

Nóvoa (1992) já havia descrito que as necessidades reais as quais os professores estão sujeitos a enfrentar são únicas, o que lhes exige capacidades reflexivas que devem estar amparadas em uma formação adequada. "Os problemas da prática profissional docente não são meramente instrumentais; todos eles comportam situações problemáticas que obrigam a decisões num terreno de grande complexidade, incerteza e de conflito de valores" (NÓvOA, 1992, p. 27).

Anteriormente à resolução, Schmitt et al. (2015) já apontavam que os cursos de formação de professores não atendiam ao desejo de possibilitar ações conscientes que conduzissem as transformações na vida das pessoas. O que vem se percebendo já há algum tempo é que a percepção do professor como um transmissor de conhecimento acabado já não cabe, por isso compete aos cursos de formação instrumentalizar os futuros professores a compreenderem que a conjuntura em que se localiza o magistério é complexa e ampla.

Hoje a profissão já não é a transmissão de um conhecimento acadêmico ou a transformação do conhecimento comum do aluno em um conhecimento acadêmico. A profissão exerce outras funções: motivação, luta contra a exclusão social, participação, animação de grupos, relações com estruturas sociais, com a comunidade... E é claro que tudo isso requer uma nova formação inicial e continuada. (IMBERNÓN, 2011, p. 14) 
Logo, o que se percebe é que o professor, dentre outros elementos, de fato necessita de uma formação sólida que não esteja amparada em concepções teóricas que determinam como ele deve proceder a partir de propostas previamente elaboradas. É necessário que se compreenda que o professor deve ser protagonista da profissão que escolheu, e para que isso ocorra, deve estar atento às relações estabelecidas com seus pares, com a comunidade escolar e, em especial, na etapa de sua formação inicial, com a cultura da escola básica.

O contato com a cultura escolar da educação básica é um elemento importante que a atual resolução que define as diretrizes curriculares para a formação de professores fez questão de destacar ao descrever a necessidade de articulação entre os níveis de ensino, como se percebe em trechos do artigo 11 da atual resolução do Conselho Nacional de Educação $n^{\circ} 2$, de $1^{\circ}$ de julho de 2015.

\begin{abstract}
A formação inicial requer projeto com identidade própria de curso de licenciatura articulado ao bacharelado ou tecnológico, a outra(s) licenciatura(s) ou a cursos de formação pedagógica de docentes, garantindo: II - efetiva articulação entre faculdades e centros de educação, institutos, departamentos e cursos de áreas específicas, além de fóruns de licenciatura; IV - interação sistemática entre os sistemas, as instituições de educação superior e as instituições de educação básica, desenvolvendo projetos compartilhados; $\mathrm{VI}$ - organização institucional para a formação dos formadores, incluindo tempo e espaço na jornada de trabalho para as atividades coletivas e para o estudo e a investigação sobre o aprendizado dos professores em formação. (BRASIL, 2015, p. 9)
\end{abstract}

Dourado (2015) acredita que as diretrizes atuais vão ao encontro das aspirações de décadas dos docentes no que refere à formação inicial e continuada, às condições de trabalho e ao salário dos professores, bem como valoriza a combinação entre o ensino superior e a educação básica. A articulação proposta "redimensiona a formação desses profissionais a partir de concepção de docência que inclui o exercício articulado nos processos ensino e aprendizagem e na organização e gestão da educação básica" (DOURADO, 2015, p. $315-316$ ).

Compreende-se ainda que proposto na legislação vigente rompa com os saberes que marcaram a formação inicial dos docentes, mas que não eram compreendidos como dotados de significados quando os futuros profissionais adentravam ao mundo real 
inerente à educação básica. Ball e Cohen (1999) destacaram esse distanciamento entre os saberes quando apontaram em seus estudos que os professores iniciantes não conseguiam interligar os saberes assimilados na universidade com as situações reais que envolviam a escola. E mais, os autores identificaram, ainda, que ao longo do tempo, os professores passaram a utilizar apenas os saberes assimilados no dia a dia de trabalho, abandonando aqueles edificados na universidade.

Ferreira (2016) destaca que no cotidiano da sala de aula o futuro professor se defronta com múltiplas situações divergentes com as quais não aprendeu a lidar durante seu curso de formação. Como consequência, não consegue o apoio proveniente dos conhecimentos adquiridos nos cursos de formação que trabalham com situações hipotéticas ou ideais, pois a realidade escolar apresenta situações únicas.

Os cursos de licenciatura precisam ultrapassar apenas a oferta do direito legal em exercer uma profissão, pois a natureza do trabalho docente que é o ensinar como uma “contribuição para o processo de humanização deve desenvolver nos alunos conhecimentos, atitudes e valores, que lhes possibilitem permanentemente construírem seus saberes-fazeres docentes, a partir das necessidades e desafios que surgem no cotidiano" (PIMENTA, 1996, p. 75).

No tocante à formação em EF, é importante destacar que em 2004, por meio do parecer CNE/CES 0058/2004, foram instituídas as Diretrizes Curriculares Nacionais para os cursos de graduação em Educação Física assegurando que os cursos de graduação precisam garantir dentre outros elementos, uma formação generalista, humanista e crítica, qualificadora da intervenção acadêmico profissional, a indissociabilidade entre teoria-prática por meio da prática como componente curricular, estágio profissional curricular supervisionado e atividades complementares (BRASIL, 2004).

Percebe-se, com as diretrizes, uma preocupação em formar um profissional que possa promover mudanças relacionadas também aos direitos das pessoas quando necessário, a partir das dimensões do conhecimento. Porém, para isso, não há uma recomendação sobre o percentual por área para a distribuição da organização dos currículos no que se refere a essas dimensões. Dessa forma, cabe a cada curso definir as competências que se almejam alcançar com o egresso (FERREIRA, 2016). 
É necessário também destacar que o termo generalista, enfatizado nas diretrizes de 2004, não pode estar associado ao significado de pulverizar os conhecimentos, pois, seu preceito guia se refere a uma base diversificada ampliada sob o objeto de estudo da EF - a Cultura Corporal de Movimento. Partindo desse teor em relação ao significado do termo generalista, compreende-se parte das críticas realizadas a estas diretrizes que rescindem com a tradição generalista e ampliada que possibilitava ao profissional trabalhar tanto no âmbito escolar quanto não escolar. (FERREIRA, 2016, p. 13)

Barbosa-Rinaldi (2008, p. 201) destaca que, na formação inicial, o desenvolvimento da competência técnica só fará sentido se estiver articulada com o cotidiano docente. Para que se tenha êxito nos espaços de atuação, o professor de EF “deve ser preparado para enfrentar e refletir, criticamente, sobre os fenômenos e as situações conflituosas presentes na EF escolar. Por isso, os cursos precisam estabelecer estreita relação com a escola".

Para Taffarel e Santos Júnior (2010), os modelos de formação de professores de EF estão submersos num cotidiano que apresenta muitos problemas, dentre eles: os relacionados aos problemas teóricos de disputa entre áreas médicas e humanas; os relacionados à oferta de condições ótimas para o funcionamento dos cursos, no que se refere à infraestrutura, salários, professores sem qualificação e falta de assistência estudantil; e, problemas de ordem curriculares no que se refere à inconsistente base teórica, gestão autoritária e ausência de articulação do ensino, pesquisa e extensão.

Alviano Jr. e Neira (2013) apontam que o currículo de formação de professores de Educação Física no Brasil ao ser construído com o objetivo de atender distintas concepções, múltiplos discursos e visões diversas de sociedade, ensino e escola, acaba proliferando uma série de discursos epistemológicos na área, o que os remete a associálos a um Frankenstein.

É necessário na docência, seja em uma aula de EF, em um centro de treinamento esportivo, na academia ou em outro lugar destinado aos profissionais da área, resgatar a complexidade do ato de lecionar. Para Rezer e Fensterseifer (2008, p. 320) isso "não deve ocorrer por decreto, mas sim, porque traz em sua esteira uma tradição, um nível de exigência intelectual, sensível, estética, corporal, enfim, um nível de exigência humana que pode ser bastante elevado". 
Diante desse contexto que envolve a formação de professores de $E F$, temos encontrado nos cotidianos escolares situações diversas com relação às práticas pedagógicas, condições de trabalho dos professores e relacionamentos com outros professores, gestores e discentes das escolas que caracterizam peculiaridades únicas desses profissionais.

No que se refere especificamente às práticas pedagógicas, observamos que ainda resiste em grande parte dos cotidianos escolares aquelas dotadas de pouco ou nenhum significado para quem dela participa. São práticas que se resumem à execução técnica de uma ou outra modalidade específica durante todo o ano letivo, ou ainda, práticas esportivas livres, cuja função dos professores é supervisionar a atividade para evitar possíveis conflitos entre os discentes durante a aula. O que se percebe é que a função exercida pelo professor poderia ser executada por qualquer outro funcionário da escola, afinal, esse tipo de supervisão não necessita de formação superior em EF ou outra qualquer. Basicamente, é o que podemos caracterizar como práticas de desinvestimento profissional.

A denominação desinvestimento profissional surge a partir do conceito adotado por Huberman (1992) que ao estudar o ciclo de vida da carreira docente, acredita que por volta dos 35 a 40 anos de experiência, os professores se concentram mais em questões voltadas para assuntos externos à escola, pois consideram que não dão conta mais de exercer suas funções como executavam anteriormente.

No entanto, para Machado et al. (2010), o desinvestimento pedagógico na EF não está centrado em um período cronológico da vida profissional do professor, como descreve Huberman (1992), mas associado aos professores que permanecem em seus locais de trabalho mas abandonam a responsabilidade de realizar um trabalho com qualidade.

No panorama atual da EF escolar é comum observar que as ações dos professores se resumem a observar os alunos realizando atividades que eles próprios escolheram ou aqueles que são possíveis de serem realizadas em virtude das condições de materiais disponibilizados. Neste tempo de execução das atividades desenvolvidas pelos alunos cabe aos professores sentar-se a sombra para folear uma revista, um jornal ou dialogar com os alunos que não estão envolvidos nas atividades. (MACHADO et al., 2010, p. 132) 
No entanto, também se faz necessário destacar que há muitos professores de EF comprometidos com a profissão, que buscam a cada aula práticas modificadoras que caracterizam as aulas como dotadas de relevância e significado para a vida dos discentes. Para esses profissionais, a escassez de materiais ou os locais inadequados não são um impedimento para que nas aulas se construam conhecimentos em EF. No entanto, não podemos afirmar que essas ações se manterão vivas ao longo dos anos de trabalho dos docentes, pois, a ausência de comprometimento da gestão escolar, dos discentes e de políticas que valorizem os professores e a própria EF, enquanto disciplina, podem comprometer as ações eficazes dos docentes comprometidos com a profissão.

As práticas modificadoras estão concentradas nas possibilidades de vivência de temas diversos relacionados à cultura corporal de movimento, como as danças, os jogos, os esportes, as ginásticas, as atividades rítmicas, as atividades circenses, conhecimento sobre o corpo e as lutas etc. Mais do que a vivência dos conteúdos, as práticas que denominamos modificadoras têm o propósito de alterar por completo as aulas caraterizadas como de desinvestimento pedagógico. Essas aulas procuram dar sentido aos conteúdos que os alunos constroem junto à mediação do professor. Para isso, é fundamental que os discentes compreendam o significado do porquê vivenciam ou experimentam determinados conteúdos, afinal, a EF deve permitir a possibilidade além da produção, da transformação do objeto de estudo da EF. Essa perspectiva corrobora com o conceito atribuído por Betti (2009) à disciplina:

uma disciplina que tem por finalidade propiciar aos alunos a apropriação crítica da cultura corporal de movimento, visando a formar o cidadão que possa usufruir, compartilhar, produzir e transformar as formas culturais do exercício da motricidade humana: jogo, esporte, ginásticas e práticas de aptidão física, dança e atividades rítmicas/expressões, lutas/artes marciais e práticas corporais alternativas. (BETTI, 2009, p. 64)

Compreendemos que o currículo do estado de São Paulo é um bom exemplo de material para ser utilizado no que se refere à diversificação de conteúdos e tratamento dispensado às estratégias de ensino e aprendizagem. No referido currículo o conhecimento construído pelos discentes valoriza o diálogo com o mundo e com outras pessoas a partir dos conhecimentos que o corpo discente já possui sobre diferentes 
manifestações corporais e de movimento, buscando ampliá-los, aprofundá-los e qualificálos criticamente (SÃO PAULO, 2011).

É importante destacarmos que o contexto escolar em que a EF está inserida sofreu modificações ao longo do tempo. Contudo, ainda carregamos rótulos que precisam ser extintos quanto às suas concepções. Especificamente no ambiente escolar é necessário que os professores de EF se façam escutados em seus anseios e pretensões. Para isso, as ações precisam ser iniciadas pelo comprometimento com o planejamento de suas aulas. Não é mais cabível que os professores não tenham claramente identificados os objetivos a serem atingidos com cada conteúdo na escola.

O diagnóstico bem realizado no início do ano pode dar subsídios para que os docentes tenham claramente identificadas quais serão as carências de materiais e de infraestrutura que podem comprometer o seu trabalho, e, assim, junto ao grupo gestor e à comunidade discente pensar em alternativas que possam suprir, ao menos em parte, os problemas identificados previamente. A análise inicial realizada nas primeiras aulas também pode trazer elementos sobre o que os discentes já sabem e quais aspectos deveriam receber maior atenção. Assim, os professores não precisarão repetir o que eles já conhecem e não planejarão atividades aquém ou além do nível de compreensão dos discentes.

Este planejamento deve expressar além dos conteúdos e da indicação da avaliação a ser realizada em cada ano escolar, as expectativas que se almejam atingir com os diversos alunos que fazem parte daquele ano letivo. Afinal, a classe pode apresentar níveis de aprendizagem diferenciados, incluindo aí alunos que foram promovidos apresentando defasagem de conhecimentos para o ano em que se encontram.

Vasconcellos (2000) destaca a importância da clareza do planejamento do professor para o processo de ensino aprendizagem, pois a ação de ensinar não deve ser compreendida como um método no qual os resultados estão definidos, afinal a sala de aula deve se constituir como um ambiente de troca de saberes e de acordos para a produção de novos conhecimentos. Logo, permitir a avaliação constante do planejamento e a participação dos alunos e da comunidade escolar como um todo é requisito fundamental para um planejamento compartilhado e democrático. 
Enfim, entendemos que o planejamento compartilhado e democrático se torna um instrumento fundamental para que se alcancem as metas educacionais traçadas no início do período letivo, logo após a realização do diagnóstico inicial. Esse planejamento está apto a mudanças ao longo de sua realização, afinal as avaliações podem apontar que as metas traçadas não estão sendo conquistado naquele momento, o que implica traçar novos caminhos.

\section{Métodos}

A metodologia escolhida foi a pesquisa descritiva qualitativa por entendermos que a mesma permite conhecer de modo apurado uma comunidade determinada, assim como os predicados relacionados ao espaço-tempo onde ela está constituída. A pesquisa descritiva expõe as características de determinada população ou fenômeno, estabelece correlações entre variáveis e define sua natureza. "Não têm o compromisso de explicar os fenômenos que descreve, embora sirva de base para tal explicação" (VERGARA, 2000, p. 47).

Segundo Selltiz et al. (1965), a pesquisa descritiva qualitativa busca descrever pormenor um fenômeno ou situação, principalmente o que está ocorrendo, para que possa compreender de modo preciso as particularidades das pessoas, das situações ou de um grupo de indivíduos, bem como na relação destes com o mundo.

\section{Sujeitos}

Constituíram-se sujeitos deste estudo 26 professores de Educação Física que se encontravam em exercício na rede pública e privada do estado do Mato Grosso, especificamente nas cidades de Cáceres, Mirassol, Poconé e Porto Esperidião. No entanto, serão objetos deste estudo, neste momento, apenas os 21 professores que lecionavam no setor público do estado. Os sujeitos foram informados sobre os objetivos da pesquisa e da não obrigatoriedade em participar ou responder todas as questões presentes no instrumento de coleta. 
A idade dos sujeitos ficou compreendida entre os 23 e 48 anos de idade. A formação acadêmica se concentrou em universidades públicas e particulares de dois estados, Mato Grosso e São Paulo, ocorrida entre o período de 1996 e 2015. Três foram os motivos que os levaram a escolher o curso de EF: amor ao esporte; identificação com o curso; por acreditarem que a EF é mais que um jogo de bola. O tempo de magistério dos sujeitos ficou entre um e 20 anos de exercício. Do total dos participantes do estudo, 14 deles possuíam pós-graduação latu sensu, uma delas na área escolar.

\section{Coleta de dados}

Para a coleta de dados utilizou-se um questionário contendo seis questões abertas, além das informações gerais que caracterizaram os sujeitos do estudo. 0 questionário foi entregue individualmente para que os professores pudessem responder e devolver na semana seguinte. Dos 35 questionários entregues, 26 foram devolvidos e, apenas 21, pertencente aos professores da rede pública de ensino, foram analisados.

\section{Análise dos dados}

Para a análise dos dados, optou-se pelos eixos temáticos a partir dos procedimentos adotados por Rinaldi (2009, p. 14), quais sejam: relacionamento entre professor e a direção da escola; a relação estabelecida entre professor e família; os principais obstáculos presentes nas aulas; a importância da formação inicial no contexto da escola; ações para minimizar as condições adversas no trabalho.

\section{Resultados e discussão}

Antes de apresentarmos e discutirmos os resultados deste estudo, julgamos ser pertinente uma breve caracterização da rede escolar do estado do Mato Grosso. Para isso, inicialmente, vamos recorrer ao material descrito na página oficial da Secretaria de Estado da Educação do Governo do Estado do Mato Grosso. 
Muitas escolas em nosso estado se encontram em situação bastante precária no tocante a instalações físicas, exigindo ampla necessidade de reformas, ampliações e melhorias, assim como existem algumas unidades que foram locadas, o que torna sua manutenção ainda mais onerosa. (MATO GROSSO, 2016, on-line)

Ainda segundo a página oficial do estado, o Mato Grosso tem em seu quadro 755 escolas de ensino regular, distribuídas por 141 municípios. Elas são subdivididas em duas Creches Escolas; 23 Centros de Educação de Jovens e Adultos (CEJA); 69 unidades escolares indígenas; cinco unidades Quilombolas; cinco unidades de Educação Especial; 142 unidades escolares de educação do Campo; 498 unidades escolares urbanas e 11 unidades confessionais (MATO GROSSO, 2016).

De acordo com Dutra (2015, p.21), as políticas e práticas educacionais adotadas no estado do Mato Grosso buscam propiciar uma educação pública de qualidade atendendo as necessidades do mundo contemporâneo. Para isso, adota o sistema Ciclado como organização estrutural do ensino fundamental, "valendo-se do percurso histórico da rede, que, há dez anos, trabalha com a organização por ciclos na perspectiva da inclusão, da educação como direito e voltada para a formação humana”.

Diante dos resultados analisados, o primeiro eixo elencado foi o relacionamento entre o professor e a direção da escola. Após os procedimentos realizados na análise dos resultados constatou-se, no que se refere ao relacionamento dos docentes com a direção escolar e ao suporte dos gestores quanto à aquisição de materiais pedagógicos e à disponibilidade de espaço físico adequado para que as aulas de EF aconteçam, que os professores acreditam haver um bom relacionamento entre eles e o grupo gestor da escola. No entanto, no que se refere especificamente ao espaço físico foi possível constatar que ainda há unidades escolares desprovidas de um local próprio para as vivências nas aulas de EF, como uma quadra poliesportiva por exemplo.

O relacionamento entre a direção e os professores é muito bom. A escola é aberta as nossas ideias e não se opõe aos conteúdos que escolhemos trabalhar. (SUJEITO 7, 2018)

Temos um bom relacionamento com a direção. Eles nos disponibilizam, dentro do orçamento da escola, materiais didáticos e internet. No 
entanto, para as aulas práticas não, pois a escola não possui espaço físico próprio e nem materiais adequados. (SUJEITO 20, 2018)

A ausência de um espaço próprio para as aulas pode transmitir à comunidade escolar a ausência de valorização da disciplina. Se nos espaços físicos está representada uma dimensão simbólica e pedagógica do lugar, que leitura e interpretação são feitas da escola que não oferece um espaço específico para uma disciplina? “... todo espaço é um lugar percebido. A percepção é um processo cultural. Por isto não percebemos espaços senão lugares, isto é, espaços elaborados, construídos. Espaços com significados e representações" (VIÑAO FRAGO, 1998, p. 105).

É inegável que as condições materiais pedagógicas e de estrutura física interferem nas questões relacionadas ao processo de ensino aprendizagem dos professores. Por mais que se esforcem para atender aos anseios da profissão e da comunidade escolar, poderão em muitos momentos não corresponder a tais expectativas por não possuírem o respaldo do poder público. A qualidade das instalações escolares de fato afeta as proposições curriculares e consequentemente a aprendizagem dos alunos nas diversas unidades que sofrem com um problema que vem se tornando comum. Essa avaliação é corroborada por Souza Lima (1998, p.31), que descreve que "o espaço físico é material riquíssimo e está sendo totalmente desprezado. Nos projetos de construções escolares não há lugar para bibliotecas, laboratórios e quadras de esportes, o que limita as possibilidades de aprendizado".

No entanto, esse não pode ser um limitador eterno do trabalho do professor, pois o planejamento educacional compartilhado realizado a cada início de ano, ao se constituir como um processo de reflexão e decisão conjunta, deve buscar alternativas para os obstáculos existentes. Como consequência da ausência de um espaço específico para as aulas de EF na escola, os sujeitos apontaram que as condições climáticas interferem decisivamente nas opções da escolha dos conteúdos a serem trabalhados com os alunos, como se observa na fala dos sujeitos 3 e 5 .

Temos um problema para a realização das aulas quando chove ou o sol está muito forte, pois nossa quadra é descoberta. (SUJEITO 3, 2018) 
Como não há um espaço específico para as aulas é preciso levar os alunos para áreas públicas que são abertas e assim enfrentamos problemas com o sol forte, a chuva e ainda, os drogados que frequentam estes lugares. (SUJEITO 5, 2018)

A constatação da ausência de espaço físico deve promover na comunidade escolar, e em especial, nas ações iniciadas pelo professor de EF, a necessidade de reivindicar junto às autoridades públicas atos que sejam revertidos em prol de soluções para o problema apresentado.

É compreensível que parte dos alunos se negue a participar das aulas quando estas ocorrem sob o forte calor. O sol forte pode causar insolação e melasmas (manchas em tom marrom na pele). Na prática, o que ocorrerá é a participação de grande parte dos alunos em sala de aula (espaço físico fechado) e uma diminuição significativa destes nas vivências dos conteúdos, quando as aulas ocorrerem em espaços abertos.

A realidade constatada neste estudo não difere de muitas outras escolas públicas no país, no entanto, também é possível encontrar na literatura um número importante de escolas públicas que conseguiram reverter uma situação negativa no que se refere aos quesitos apontados devido à mobilização ativa da comunidade escolar, como demonstram os estudos de Santos, Mendes e Ladislau (2014) e Rosa, Ivo e Marin (2016).

Vago (1999) aponta que os docentes não deveriam se concentrar unicamente no planejamento de suas aulas, mas como sujeitos sociais praticantes, deveriam também se envolver na concretização de novas práticas a favor da instituição e das práticas escolares.

O segundo eixo elencado foram os principais obstáculos presentes nas aulas de EF. No que se refere aos principais obstáculos que os professores encontram em suas aulas de $E F$, os docentes apontaram que, além do espaço físico ausente ou inadequado e da escassez de materiais pedagógicos para as vivências, que a aversão dos alunos frente aos conteúdos propostos pelos professores e a indisciplina dificultam o processo de ensino aprendizagem.

Falta de materiais e espaços específicos e principalmente a resistência dos alunos para desempenhar atividades diversificadas. (SUJEITO 13, 2018) 
Não aceitação por parte dos alunos em relação aos conteúdos propostos. São indisciplinados e apenas praticam o que desejam que se resuma a uma ou outra modalidade esportiva. (SUJEITO 19, 2018)

Já há algum tempo, um número considerável de professores vem buscando por meio de práticas modificadoras, transformar a EF escolar numa disciplina que de fato introduza e integre o aluno na cultura corporal, formando o cidadão que vai produzi-la, reproduzi-la e transformá-la; instrumentalizando-o para usufruir de jogos, esportes, danças, lutas e ginásticas em benefício do exercício crítico da cidadania e da melhoria da qualidade de vida (BETTI; ZULIANI, 2002).

No entanto, ainda temos em nossa disciplina na escola docentes que, por uma série de motivos, desvalorizam o profissional de EF, ao não possibilitarem em suas aulas, que exista crescimento intelectual que propicie aos discentes o benefício uso pleno da cultura corporal de movimento.

Essa ausência de crescimento intelectual dos discentes acarreta a desvalorização da disciplina enquanto promotora de vivências que se opõe ao tradicionalismo. Como uma disciplina escolar desvalorizada, não há porque deixar de reduzir sua carga horária ou o número de aulas semanais ofertadas. Com professores desmotivados o conteúdo se torna repetitivo e, para evitar conflitos que levem o professor a sair da zona de conforto instalada, o conteúdo ofertado é aquele pelo qual os discentes têm preferência, o que o torna conteúdo anual.

Essa preferência por um conteúdo específico caminha em direção contrária aos objetivos dos professores dotados de práticas modificadoras; como consequência, brotam a rejeição pelo professor e pelos conteúdos propostos, bem como, a indisciplina ocasionada pela mudança do paradigma instalado que atendia aos interesses de parte dos alunos. O docente em EF tem o compromisso profissional de possibilitar a construção do conhecimento do maior número possível de conteúdos. Para isso, temas como jogos, esportes, ritmos, lutas, atividades circenses, atividades radicais e de aventura e ginásticas precisam ser apresentados, vivenciados e discutidos com a população estudantil.

No que se refere à indisciplina escolar, Aquino (1998) acredita que ela decorre do conceito atribuído pelos profissionais da educação ao termo. Quando estes profissionais 
atribuem o conceito de disciplina como comportamentos conduzidos por um contexto de normas estabelecidas, logo se subentende que a quebra das regras estabelecidas tem origem na indisciplina de quem não as cumpre. Dessa forma o autor afirma que,

a compreensão do conceito de indisciplina é decorrente da nossa conceituação do que vem a ser a disciplina, para o autor, se compreendermos a disciplina por [...] comportamentos regidos por um conjunto de normas, a indisciplina poderá ser traduzida de duas formas: 1) a revolta contra essas normas; 2) o desconhecimento delas. No primeiro caso, a indisciplina traduz-se por uma forma de desobediências insolente; no segundo, pelo caos dos comportamentos, pela desorganização das relações. (AQUINO, 1998, p. 10)

Brito (2007) realizou um trabalho cujo objetivo foi investigar a concepção de indisciplina entre docentes de EF. O autor constatou que a indisciplina na EF é caracterizada quando o aluno não participa da aula evadindo-se da mesma, sem porém, incomodar os demais com a sua atitude. Concluiu o estudo afirmando que a indisciplina é percebida como uma tentativa de romper com a manutenção das práticas pedagógicas estabelecidas.

Bercht, Brino e Reis (199?) ao investigarem como uma determinada escola da rede pública atuava frente aos problemas indisciplinares nas aulas de EF, detectou que os problemas mais corriqueiros se referiam às agressões físicas entre os alunos (eventos isolados) e discussões entre alunos e entre alunos e professor. As situações de indisciplina não eram frequentes e na grande maioria das vezes eram resolvidas por meio do diálogo.

Os professores envolvidos no estudo descreveram que não receberam orientações ou auxílio do grupo gestor da escola sobre como agirem diante dos casos apontados. Relataram ainda que a escola não possui serviço de orientação educacional, sendo comum o registro da ocorrência, intimação aos pais e suspensão do aluno. Apontam também, como sugestão para a melhora na diminuição dos problemas disciplinares, a necessidade da atuação conjunta entre escola e pais dos alunos (BERCHT; BRINO REIS, 199?). 
Se associarmos a indisciplina à quebra das regras estabelecidas no ambiente escolar, é necessário que essas regras não sejam apenas apresentadas e, sim, construídas em conjunto no ambiente escolar, em especial, com os discentes. Essa construção conjunta pode inibir alegações de desconhecimento das regras estabelecidas e tem uma possibilidade maior de cumprimento, uma vez que os sujeitos foram protagonistas na elaboração do contrato social estabelecido.

O terceiro eixo elencado foi a relação estabelecida entre professor e família. Quando os docentes foram indagados sobre a relação estabelecida entre os professores e as famílias dos alunos que frequentam a unidade escolar, os sujeitos destacaram que há pouco envolvimento da família com a escola, mesmo quando há um chamamento advindo do grupo de professores ou gestores, esta se ausenta de suas responsabilidades educacionais.

A direção chama os responsáveis pelas crianças para comparecerem à escola, mas estes não aparecem. Há pais que eu nunca vi aqui na escola desde quando eu comecei a lecionar. (SUJEITO 13, 2018)

No nosso caso, como são alunos do EJA, não há participação ativa da família, pois a maioria dos alunos já é mais velha. (SUJEITO 2, 2018)

Reis (2008), em sua tese de doutorado, cujo objetivo foi identificar os fatores que promovem o envolvimento parental das famílias de nível socioeconômico baixo na escola, e propor estratégias de envolvimento parental junto das escolas e dos professores, investigou por meio de questionário três dimensões do envolvimento parental em 591 sujeitos de escolas portuguesas: a comunicação entre a escola e a família; o envolvimento da família em atividades na escola; e, o envolvimento da família em atividades de aprendizagem em casa.

A análise dos resultados permitiu identificar um grupo de 24 famílias de nível socioeconômico baixo, que apresentava, ao contrário do que era esperado, um nível alto de envolvimento parental na escola e em casa.

Através da realização de entrevistas a famílias deste grupo, procedeu-se à identificação de fatores que estavam associados a um alto envolvimento parental tendo-se apurado como significativos: i) o modelo de proximidade que o professor estabelece com os pais, baseado num conhecimento real de cada aluno e de cada família; ii) a partilha de 
informação e a forma como a comunicação se processa, o que permite aos pais minimizarem os anseios, as preocupações e dificuldades, bem como, uma participação mais ativa na escola, face a um maior apoio pedagógico; e, por último, iii) um acompanhamento mais efetivo das atividades de aprendizagem em casa e nos tempos livres. (REIS, 2008, p. 15)

Reis (2008) destacou ainda que o envolvimento da família foi facilitado devido às expectativas positivas dos pais com os filhos. No entanto, a autora aponta que com o avançar das séries o envolvimento dos pais se tornou mais complicado devido, dentre outros fatores, à comunicação com a escola e o professor, e, na compreensão de certas áreas de ensino, decorrentes de uma insuficiente formação acadêmica. Dessa forma, a autora aponta a necessidade de uma formação inicial que contemple a sensibilização e abordagens mais coerentes para se estabelecer estratégias criativas que forneçam às famílias subsídios de apoio em todo o processo educacional.

Oliveira e Marinho-Araújo (2010) destacam que a partir das distintas perspectivas e abordagens relativas à relação escola e família, as produções científicas estão organizadas em dois grupos denominados de sociológico e psicológico. Na perspectiva sociológica, a relação família e escola é percebida em função das questões ambientais e culturais. Quando há um conflito entre os anseios dessas duas instituições, é atribuída à família a responsabilidade pelas disparidades escolares. Logo, cabe a elas adotar as mesmas estratégias de socialização adotadas pela escola, o que faz com que a escola acabe ampliando seus âmbitos de ação.

No enfoque psicológico, as questões relacionadas à ordem emocional e afetiva são destaques quanto à compreensão da relação família e escola e da ocorrência do fracasso escolar. Uma dinâmica familiar positiva é responsável pelo bom desempenho do aluno. Assim, os determinantes psicológicos que constam na estrutura familiar são os grandes responsáveis por qualquer desencontro entre os objetivos e valores de ambas as instituições. Logo, os professores dotados de algum conhecimento em psicologia conduzem o discurso psicológico para dentro da sala de aula avaliando e analisando o comportamento dos alunos (OLIVEIRA; MARINHO-ARAÚJO, 2010).

O quarto eixo elencado foi a importância da formação inicial no contexto da escola. Os docentes foram indagados se, se sentiam preparados para trabalhar com a 
diversidade de conteúdos que compõe o leque de opções que a EF possibilita, como dança, lutas e ginástica, por exemplo. As repostas apontaram que há dificuldades em se construir conhecimentos com parte desses conteúdos pela ausência de afinidade do professor com o conteúdo, pelas raríssimas aproximações entre a realidade da escola e os conhecimentos construídos na universidade e pela dificuldade em romper com o desejo do que os alunos querem e aquilo que os professores planejaram.

Sempre busco me atualizar na área, mas a introdução de alguns dos conteúdos não é bem aceita pelos alunos. A universidade não nos preparou para conviver com o "não" dos alunos. (SUJEITO 5, 2018)

Para trabalhar com a teoria, me encontro preparado, mas com a prática, tenho muita dificuldade. Faltou na universidade nos ensinarem como lidar com os conflitos e a indisciplina quando propomos algo que não vai ao encontro do que nossos alunos desejam. (SUJEITO 8, 2018)

Ferreira (2016), em sua tese de doutorado sobre o trabalho colaborativo na EF escolar já havia apontado que no cotidiano da sala de aula, o professor defronta-se com múltiplas situações divergentes com as quais não aprende a lidar durante seu curso de formação. Por não constarem nos referenciais teóricos e técnicos, o professor não consegue o apoio proveniente dos conhecimentos adquiridos no curso de formação, pois estes não se aproximaram da realidade escolar.

Imbernón (2011) destaca que a profissão não deve mais se limitar à transmissão de um conhecimento teórico, acadêmico, mas de formar um profissional que exerça outras funções tão importantes quanto às destacadas anteriormente, como: as que transitam pela motivação, a luta contra a exclusão social, as participações, as animações de grupo, relação entre universidade e escola, e as relações com estruturas sociais e a comunidade.

Os cursos de licenciatura não devem ser constituídos de atividades burocráticas. Espera-se que se forme o professor ou ao menos, que a formação inicial colabore para o exercício da atividade docente, pois professorar não pode ser uma atividade burocrática. A natureza do trabalho docente, que é o ensinar como uma contribuição para o processo de humanização "deve desenvolver nos alunos conhecimentos, atitudes e valores, que 
Ihes possibilitem permanentemente construírem seus saberes-fazeres docentes, a partir das necessidades e desafios que surgem no cotidiano" (PIMENTA, 1996, p. 75).

Ferreira (2016) acredita que o Programa Institucional de Bolsa de Iniciação à Docência (PIBID), proposto pelo MEC/Capes em 2007 e regulamentado pelo Decreto n. 7219/2010, pode ser considerado como uma ação governamental que aproxima a universidade e escola ao criar condições favoráveis à inserção dos professores em formação no ambiente escolar. Essa aproximação possibilita que os futuros professores possam confrontar a realidade escolar com os conhecimentos produzidos na universidade, o que consequentemente os credencia a construir novas teorias a partir de suas experiências in loco.

Para Ciríaco e Costa (2016) cabe à formação inicial discutir formas de organização do trabalho docente, a partir do estágio e as problematizações originárias das atividades desta disciplina. Não deve ser uma prática instrumental, pois a disciplina precisa possibilitar elementos para a integração do processo formativo do futuro professor com o campo de trabalho deste profissional, a partir de análises reflexivas entre os dados coletados com estágio e os conhecimentos construídos na universidade (PIMENTA; LIMA, 2004).

Nosso quinto eixo elencado foram às ações para minimizar as condições adversas no trabalho. Ainda foi perguntado aos docentes quais ações eram realizadas por eles para minimizar as condições de trabalho inapropriadas, bem como, para resolver as situaçõesproblemas mais corriqueiros nas salas de aula. Os sujeitos da pesquisa utilizam diversas estratégias para que os obstáculos pudessem ser transpostos, como se observa abaixo.

Utilizo a criatividade, materiais alternativos e adaptações para que as aulas se tornem atrativas. (SUJEITO 11, 2018)

Como não temos espaço específico na escola, levo meus alunos às praças públicas que se localizam próximo à escola e procuro confeccionar materiais alternativos para a realização das atividades planejadas. (SUJEITO 28, 2018)

É possível evidenciar na fala dos sujeitos a ausência de ações do poder público em favor da escola, quando os docentes destacam a carência de espaço e de materiais para 
suas práticas pedagógicas. No entanto, Silvio e Damazio (2008), ao destacarem o descaso com a escola pública, apontam que os espaços e as condições disponíveis devem ser adaptados, reinventados e criados a partir do entendimento do docente e de sua realidade profissional. "Dependendo da concepção de ensino e da perspectiva curricular adotada pelo professor, espaços alternativos e obstáculos podem se transformar em recursos para possibilitar a criatividade, a inovação e a construção de práticas diversificadas".

Outro estudo interessante sobre a utilização de materiais alternativos para superar a ausência de materiais específicos da EF na escola pública foi realizado por Sebastião e Freire (2009). No estudo em questão foi possível verificar que os professores utilizam o material alternativo para superar escassez de materiais, o que evidencia a inquietação do corpo docente em possibilitar aulas de EF com estímulos diversos. O estudo também apontou que essas ações são realizadas individualmente, sem a construção de um projeto coletivo, o que, na percepção dos autores, levanta a hipótese de que a construção de materiais seja uma tendência atual entre os professores.

Infelizmente, a ausência de investimento em grande parte das escolas públicas não atende ao desejo da sociedade que ambiciona, dentre outros requisitos, uma escola pública que ofereça no mínimo um ambiente propício à construção de conhecimentos. No entanto, os professores, e, em especial, os de EF, não podem transformar suas aulas em aulas livres, nas quais cada aluno, ou grupo de alunos, determina o quer fazer na EF sob a alegação de que não há materiais disponíveis para a aula. Salgado (2017), destaca que é fundamental que os professores de EF, junto a gestão escolar e aos órgãos educacionais, busquem alternativas que levem à solução dos problemas atuais, direcionando os recursos financeiros para a EF. As aulas livres não podem substituir a qualidade de ensino na EF escolar.

A elaboração de materiais alternativos construídos junto aos alunos, até mesmo para que estes valorizem os equipamentos criados é um ato de comprometimento profissional dos professores que deve ser acompanhado de atitudes de reivindicação junto ao poder público, para que assuma suas responsabilidades e não se acomode pela ausência de tais ações, sanadas a priori pelo corpo docente. 


\section{Considerações finais}

A EF escolar transformou-se ao longo do tempo, de modo a satisfazer aos interesses das personagens que conduziam o processo ensino-aprendizagem nos ambientes destinados a este fim. Deste modo, o que se percebe, é que a formação inicial, precisa subsidiar as práticas dos futuros docentes com saberes que possam estar articulados ao cotidiano docente e aos conhecimentos produzidos ao longo do tempo.

Além de um possível comodismo do profissional, dois fatores significativos foram apontados neste estudo como limitadores de práticas eficazes nas aulas de EF: a ausência de uma formação acadêmica que valorize o aluno real da educação básica em oposição ao aluno ideal, e, a ausência de materiais pedagógicos e espaços físicos mínimos para que o professor possa ministrar suas aulas a partir das condições que se fazem necessárias.

Na contramão dos elementos limitadores que prejudicam as aulas de EF temos as ações dos professores modificadores, que dentre outras, procuram enfrentar as resistências dos alunos diante de conteúdos não corriqueiros e optam pela confecção de materiais alternativos e a utilização de espaços para além da escola, visando possibilitar aulas de EF próximas às recomendadas e reproduzidas como exemplares.

É necessário que os professores de EF demarquem seus territórios a partir de suas presenças nas unidades escolares. Para isso a comunidade escolar precisa entender qual é a função dessa disciplina na escola. Sua existência não pode se limitar a um momento de diversão ou de fazeres que nada têm a ver com a vida escolar dos alunos, afinal, as disciplinas que conquistaram seus espaços nesse ambiente têm uma demarcação solidificada que as fazem receber os rótulos de importantes para a aprendizagem dos alunos. 


\section{Referências}

ALVIANO JR, Wilson; NEIRA, Marcos Garcia. Formação inicial em educação física e currículo: uma proposta sob a ótica de seus autores. Revista Mackenzie de Educação Física e Esporte, São Paulo, v. 12, n. 1, 2013. p. 117-138.

AQUINO, Júlio Groppa. A indisciplina e a escola atual. Revista da Faculdade de Educação, São Paulo, v. 24, n. 2, 1998. p. 181-204.

BALL, Deborah Loewenberg; COHEN, David. Developing practice, developing practitioners: toward a practice-based theory of professional development. In: DARLINGHOMMOND, L.; SKYES, G. (eds.), Teaching as the learning professional: handbook of policy and practice. San Francisco: Jossey-Bass, 1999. p. 3-32.

BARBOSA-RINALDI, leda Parra. Formação inicial em educação física: uma nova epistemologia da prática docente. Revista Movimento. Porto Alegre, v. 14, n. 03, p. 185207, set./dez. de 2008.

BENVEGNÚ JÚNIOR, Arnaldo Elói. Educação física escolar no Brasil e seus resquícios históricos. Revista de Educação do IDEAU, Caxias do Sul, v. 6, n. 13, jan./jul., 2011. p. 1-15.

BERCHT, Vanessa; BRINO, Cintia; REIS, Luciana. Indisciplina nas aulas de educação física: como é vista por diretores, professores e alunos. Porto Alegre: UFRGS, \{199?\} Disponível em: http://www.penta.ufrgs.br/edu/dee/disci.htm. Acesso em: 20 abr. 2006.

BETTI, Mauro. Educação física escolar: ensino e pesquisa-ação. ljuí: Ed. da Unijuí, 2009.

BETTI, Mauro; ZULIANI, Luiz Roberto. Educação física escolar: uma proposta de diretrizes pedagógicas. Revista Mackenzie de Educação Física e Esporte, São Paulo, v. 1, n. 1, 2002. p. 73-81.

BRASIL. Conselho Nacional de Educação. Câmara de Educação Superior. Parecer CNE/CES 58/2004. Brasília (DF), 2004. Disponível em:

<http://www.confef.org.br/extra/juris/mostra_lei.asp?ID=33>. Acesso em: 01 set. 2015.

BRASIL. Conselho Nacional de Educação. Define as diretrizes curriculares nacionais para a formação inicial em nível superior (cursos de licenciatura, cursos de formação pedagógica para graduados e cursos de segunda licenciatura) e para a formação continuada.

Resolução CNE/CP n. 02/2015. Brasília (DF) MEC, 2015. Disponível em:

$<$ http://pesquisa.in.gov.br/imprensa/jsp/visualiza/index.jsp?data=02/07/2015\&jornal=1\& pagina $=8 \&$ totalArquivos=72>. Acesso em 12 jun. 2016.

BRITO, Clóvis da Silva. A indisciplina na educação física escolar. 2007. Dissertação (Mestrado em Educação) - Programa de Mestrado em Educação, Universidade Tuiuti do Paraná, Curitiba, 2007. 
CIRÍACO, Klinger Teodoro; COSTA, Milaine Menezes da. Da formação inicial ao ingresso na carreira docente. Revista Formação Docente, Belo Horizonte, v. 8, n. 1, jan./jun., 2016. p. 525 .

DAMAZIO, Marcia Silva; SILVA, Maria Fatima Paiva Silva. O ensino da educação física e o espaço físico em questão. Pensar a Prática, Goiânia, v. 11, n. 2, p. 197-207, maio/ago., 2008.

DOURADO, Luiz Fernandes. Diretrizes curriculares nacionais para a formação inicial e continuada dos profissionais do magistério da educação básica: concepções e desafios.

Educ. Soc., Campinas, v. 36, nº. 131, p. 299-324, abr.jun., 2015.

DUTRA, Ana Maria Tessele. Abandono escolar na rede pública estadual de mato grosso: entraves para o acesso ao ensino médio. 2015. Dissertação (Mestrado em Gestão e Avaliação da Educação Pública) Programa de Pós-Graduação Profissional em Gestão e Avaliação da Educação Pública. Universidade Federal de Juiz de Fora, Juiz de Fora, 2015.

FAGGION, Carlos Alberto. A prática docente dos professores de educação física no ensino médio das escolas públicas de Caxias do Sul. Do Corpo: Ciências e Artes, Caxias do Sul, v. 1, n. 2, jul./dez., 2011. p. 1-24.

FERREIRA, Robson Alex. Trabalho colaborativo na educação física escolar: estratégias para a formação de professores e inclusão. 2016. Tese (Doutorado em Educação) Programa de Pós Graduação em Educação, Universidade Estadual Paulista, Faculdade de Ciências e Tecnologia. Presidente Prudente, 2016.

GATTI, Bernadete Angelina. Formação inicial de professores para a educação básica: pesquisas e políticas educacionais. Est. Aval. Educ., São Paulo, v. 25, n. 57, p. 24-54, jan./abr., 2014.

HERCULANO, Marcia Cipriano. Afetividade na relação professor-aluno: significados sob o olhar do professor do ensino médio. 2011. Dissertação (Mestrado em Educação) -

Universidade Estadual do Ceará, Fortaleza, 2011.

HUBERMAN, Michael. O ciclo de vida profissional dos professores. In: NÓVOA, A. (org.). Vidas de professores. 2. ed. Portugal: Porto Editora, 1992. p. 31-61.

IMBERNÓN, Francisco. Formação docente e profissional: forma-se para a mudança e a incerteza. 9. ed. São Paulo: Cortez, 2011. v. 14.

LOYOLA, Rosângela da Conceição; FONTE, Sandra Soares Della; FIGUEIREDO, Zenólia Christina Campos. Experiências profissionais e os sentidos atribuídos à educação física em contexto escolar. Movimento, Porto Alegre, v. 17, n. 1, p. 177-193, jan./mar. 2010.

MACHADO, Thiago da Silva; BRACHT, Valter; FARIA, Bruno de Almeida; MORAES, Claudia; ALMEIDA, Ueberson; ALMEIDA, Felipe Quintão. As práticas de desinvestimento pedagógico na educação física escolar. Revista Movimento, Porto Alegre, v. 16, n. 02, p. 129-147, abr./jun. 2010. 
MATO GROSSO. Secretaria da Educação. Inscrições para PPP de reformas e construção de escolas vão até sexta-feira. Cuiabá: Secretaria de Educação, 2016. Disponível em: http://www2.seduc.mt.gov.br/-/inscricoes-para-ppp-de-reformas-e-construcao-de-escolasvai-ate-sexta-feira. Acesso em: 10 abr. 2019.

NÓVOA, Antonio. Os professores e a sua formação. Lisboa: Publicações Dom Quixote, 1992.

OLIVEIRA, Rogério Cruz; DAOLIO, Jocimar. Educação Física, prática pedagógica e nãodiretividade: a produção de uma "periferia da quadra". Educação em Revista, Belo Horizonte, v. 30, n. 2, p. 71-94, abr./jun. 2014.

OLIVEIRA, Cynthia Bisinoto Evangelista; MARINHO-ARAÚJO, Claisy Maria. A relação família-escola: intersecções e desafios. Estudos de Psicologia, Campinas, v. 27, n. 1, p. 99108, jan./mar. 2010.

PIMENTA, Selma Garrido. Formação de professores: identidade e saberes da docência. In: PIMENTA, S. G. (coord.). Pedagogia, ciência da educação? São Paulo: Cortez, 1996.

PIMENTA, Selma Garrido; LIMA, Maria Socorro Lucena. Estágio e docência. 2. ed. São Paulo: Cortez, 2004.

REIS, Maria Paula Ivens Ferraz Colares Pereira dos. A relação entre pais e professores: uma construção de proximidade para uma escola de sucesso. 2008. Tese (Doutorado em Educação Infantil e Familiar Investigação e Intervenção Psicopedagógica) - Universidade de Málaga, E. S. E. João de Deus. Espanha, 2008.

REZER, Ricardo; FENSTERSEIFER, Paulo. Evaldo. Docência em educação física: reflexões acerca de sua complexidade. Revista Pensar a prática, Goiânia, v. 11, n. 3, p. 319-329, set./dez.2008.

RINALDI, Renata Portela. Desenvolvimento profissional de formadores em exercício: contribuições de um programa online. 2009. Tese (Doutorado em Educação) Universidade Federal de São Carlos, São Carlos, 2009.

ROSA, Cleiton Luís Amaral da; IVO, Andressa Aita; MIRIN, Elizara Carolina. Espaços físicos e materiais didáticos: repercussões na educação física escolar. Biomotriz, v. 10, n. 02, p. 51-65, dez./2016. Disponível em:

<http://revistaeletronica.unicruz.edu.br/index.php/BIOMOTRIZ/article/view/409>. Acesso em: 09 abr. 2019.

SALGADO, Simone da Silva. Gestão e educação física escolar: uma mudança de postura para uma mudança de cultura. Temas em Educação Física Escolar, Rio de Janeiro, v. 2, n. 1, jan./jun., Rio de Janeiro, 2017. Disponível em: https://cp2.g12.br/ojs/index.php/temasemedfisicaescolar/article/view/1140/843. Acesso em: 13 abr. 2019. 
SANTOS, Nilvânia de Souza; MENDES, Jéssica de Souza; LADISLAU; Carlos Rogério. Educação física escolar: dificuldades e estratégias. In: CONGRESSO SUDESTE DE CIÊNCIAS DO ESPORTE, 2014, p. 1-3, Lavras. Anais [...]. Lavras: [s.n.], 2014.

SÃO PAULO (Estado) Secretaria da Educação. Currículo do Estado de São Paulo: Linguagens, códigos e suas tecnologias. 2. ed. São Paulo: Secretaria da Educação, 2011.

SCHMITT, Jessica Aline; FRANK, Robson; BORELLA, Douglas Roberto; HARNISCH, Gabriela Simone; STORCH, Jalusa Andreia. Percepção dos acadêmicos de Educação Física em relação à formação profissional para atuação junto aos alunos com deficiência. Revista Kinesis, Santa Maria, v. 33, n. 1, jan./jun., 2015. p. 40-54.

SEBASTIÃO, Luciane Lima; FREIRE, Elisabete dos Santos. A utilização de recursos materiais alternativos nas aulas de educação física: um estudo de caso. Revista Pensar a Prática, Goiânia, v. 12, n. 3, 2009. p. 1-12.

SELLTIZ, Claire; WRIGHTSMAN, Lawrence Samuel; COOK, Stuart. Métodos de pesquisa das relações sociais. São Paulo: Herder, 1965.

SILVA, Maria Fatima Paiva; DAMAZIO, Márcia Silva. O ensino da educação física e o espaço físico em questão. Revista Pensar a Prática, Goiânia, v. 11, n. 2, 2008. Disponível em: https://www.revistas.ufg.br/fef/article/view/3590/4066. Acesso em: 2 abr. 2017.

SOUZA LIMA, Mayumi Watanabe. Espaços educativos uso e construções. Brasília, MEC, 1998.

SUJEITO 2. [Entrevista cedida a] Robson Alex Ferreira, Cáceres (MT), 09 mar. 2018.

SUJEITO 3. [Entrevista cedida a] Robson Alex Ferreira, Cáceres (MT), 09 mar. 2018.

SUJEITO 5. [Entrevista cedida a] Robson Alex Ferreira, Poconé (MT), 15 mar. 2018.

SUJEITO 7. [Entrevista cedida a] Robson Alex Ferreira, Cáceres (MT), 01 mar. 2018.

SUJEITO 8. [Entrevista cedida a] Robson Alex Ferreira, Cáceres (MT), 01 mar. 2018.

SUJEITO 11. [Entrevista cedida a] Robson Alex Ferreira, Porto Esperidião (MT), 23 mar. 2018.

SUJEITO 13. [Entrevista cedida a] Robson Alex Ferreira, Cáceres (MT), 03 mar. 2018.

SUJEITO 19. [Entrevista cedida a] Robson Alex Ferreira, Mirassol (MT), o6 abr. 2018.

SUJEITO 20. [Entrevista cedida a] Robson Alex Ferreira, Mirassol (MT), 06 abr. 2018.

SUJEITO 28. [Entrevista cedida a] Robson Alex Ferreira, Mirassol (MT), 06 abr. 2018. 
TAFFAREL, Celi Nelza Zulke; SANTOS JÚNIOR, Claudio de Lira. Formação humana e formação de professores de educação física: para além da falsa dicotomia licenciatura $X$ bacharelado. In: TERRA, D. V.; SOUZA JÚNIOR, M. Formação em educação física \& ciências do esporte: políticas e cotidiano. São Paulo: Aderaldo e Rothschild, 2010.

TENÓRIO, Jederson Garbin; SILVA, Cinthia Lopes. Educação física escolar e a não participação dos alunos nas aulas. Ciência em Movimento, Porto Alegre, Ano 15, n. 31, 2013. p. 71-80.

VAGO, Tarcísio Mauro. Início e fim do século XX: maneiras de fazer educação física na escola. Cadernos CEDES, Campinas, v. 19, n. 48, p. 31-50, 1999.

VASCONCELLOS, Celso dos Santos. Planejamento: projeto de ensino aprendizagem e projeto político-pedagógico. 7 ed. São Paulo: [s.1], 2000.

VERGARA, Sylvia Constant. Projetos e relatórios de pesquisa em administração. 3. ed. São Paulo: Atlas, 2000.

VIÑAO FRAGO, Antonio. Por uma história de la cultura escolar: enfoques, cuestiones, fuentes. In: CONGRESO DE LA ASOCIACION DE HISTORIA CONTEMPORÁNEA, 3, Valladolid, 1998. Anais [...]. Valladolid: Universidad de Valladolid, 1998. Tema: Culturas y cicilizaciones. p. 167-183.

Recebido em: 15/05/2018

Revisões requeridas: 26/02/2019

Aprovado em: 16/05/2019

Universidade do Estado de Santa Catarina - UDESC Programa de Pós-Graduação em Educação - PPGE

Revista Linhas

Volume 20 - Número 44 - Ano 2019

revistalinhas@gmail.com 